Research Article

\title{
Molecular Spectroscopic (FTIR and UV-Vis) and Hyphenated Chromatographic (UHPLC-qTOF-MS) Analysis and In Vitro Bioactivities of the Momordica balsamina Leaf Extract
}

\author{
X. E. Mabasa, L. M. Mathomu, N. E. Madala, E. M. Musie, and M. T. Sigidi \\ Department of Biochemistry and Microbiology, Faculty of Sciences, Agriculture and Engineering, University of Venda, \\ Private Bag X5050, Thohoyandou, Limpopo, South Africa
}

Correspondence should be addressed to M. T. Sigidi; muedi.sigidi@univen.ac.za

Received 7 June 2021; Accepted 9 September 2021; Published 28 September 2021

Academic Editor: Jayanta Kumar Patra

Copyright (C) 2021 X. E. Mabasa et al. This is an open access article distributed under the Creative Commons Attribution License, which permits unrestricted use, distribution, and reproduction in any medium, provided the original work is properly cited.

Momordica balsamina (M. balsamina) is a medicinal herb comprising health-promoting secondary metabolites. This study was aimed to profile bioactive compounds in the methanolic extract of $M$. balsamina leaves using molecular spectroscopic (UV-Vis and FTIR) and hyphenated chromatographic (UHPLC-qTOF-MS) techniques and evaluate the biological (in vitro anti-inflammatory and cytotoxicity) activities of the extract. The preliminary phytochemical screening tests revealed the presence of cardiac glycosides, flavonoids, saponins, tannins, and terpenoids. The UV-Vis profile revealed various absorption bands ranging from 200 to $750 \mathrm{~nm}$, indicating the presence of flavonoids, phenolic compounds, tannins, terpenoids, carotenoids, chlorophyll, and alkaloids. FTIR spectra confirmed the presence of alkaloids, flavonoids, terpenes, anthraquinones, and phenolic compounds. A high-resolution and accurate mass spectrometer (LC-QTOF-MS model LC-MS-9030 instrument) was used, and the results confirmed the presence of flavonoid aglycones, such as quercetin, isorhamnetin, and kaempferol, as well as pseudolaroside A and dicaffeoylquinic and feruloyl isocitric acids. To the best of our knowledge, this is the first report of pseudolaroside A dimer and feruloyl isocitric acid in M. balsamina leaves. In vitro cytotoxicity assay showed that the extract was nontoxic against human colorectal adenocarcinoma (HT29 and Caco2), Vero, and RAW 264.7 cells. However, the extract showed anti-inflammatory activity on RAW 264.7 cells. The study confirmed that $M$. balsamina leaves contain nontoxic secondary metabolites that may play a pivotal role in human health as anti-inflammatory agents.

\section{Introduction}

Momordica balsamina (Cucurbitaceae) is generally known as African cucumber or pumpkin, Balsam apple, or pear [1]. It is characterized by a bitter taste attributed to phytocompounds, such as alkaloids and cucurbitacins [2-4]. Other phytochemical studies have reported that this plant may also contain flavonoids, phenols, sterols, and anthraquinones $[5,6]$. These have been reported to exhibit a wide range of biological activities such as anti-inflammatory [4], antiplasmodial [7], antidiabetic [8, 9], antidiarrheal $[5,10]$, antiviral $[1,5,10]$, antibacterial $[5,10-14]$, and cardiovascular activity [2].

In certain regions of South Africa, these leaves are used as a remedy for sugar diabetes and chronic hypertension; however, this has no scientific backing [2]. In most villages, Momordica paste is used to eliminate intestinal worms in children and prevent irritation in anus. This is done by applying the paste externally on the anus as highlighted by Nagarani et al. [4]. Momordica balsamina has also shown the potential to treat gastroenteritis [13], strongly suggesting that these leaves may be used to treat gut-related infections. Therefore, plant profiling is crucial in order to link the phytocompounds with the biological activities of the plants.

Recently, the use of sophisticated techniques and scientific methods to profile and validate phytochemical compounds in medicinal plants has become more reliable [15]. In order for the herbal infusions to sustain quality, their safety status and effectiveness must meet the quality health 
standard [16]. A range of analytical methods can be used in assessing the degree of chemical purity of phytomedicines [16].

Chromatography and spectroscopy have become more effective and reliable tools used for phytochemical analysis [17]. Fourier transform infrared (FTIR) spectroscopy is used to characterize and identify functional groups [18]. Ultraviolet-visible spectrophotometry (UV-Vis) is related to photon spectroscopy in the UV-visible region $[18,19]$. This technique uses light that is in the visible ranges of the electromagnetic spectrum $[18,19]$. The colour of chemicals involved affects the absorption, and molecules undergo electron transition in these ranges [18].

Analysis of complex media using ultraviolet-visible (UVVis) spectroscopy is a disadvantage due to limitation by inherent difficulties when it comes to assigning peaks to any constituents in the system [20]. Therefore, the UV-Vis findings must be supplemented with other analytical techniques, such as GC-MS or LC-MS, for appropriate phytocompound profiling and constituent identification. Hence, in the present study, the extract was further subjected to hyphenated chromatographic technique (UHPLC-qTOFMS) to identify the phytochemical constituents present in $M$. balsamina. The use of mass spectrometry (MS) in the development of plant metabolomics has made profiling multiple compounds, such as flavonoids and many more, possible [3, 21, 22].

The dependence on herbal concoctions prepared from plants, such as M. balsamina, has recently increased due to the severity and escalating burden of various diseases in humans. The continual usage and overharvesting of these herbs for medicinal purposes bring an urge to scientifically validate the biological effects these extracts might have [23].

Inflammation is a crucial and complex host's defensive mechanism that is intended to eliminate the initial cause of cell injury induced by microbial infections [24]. Initially, immune cells migrate from blood vessels and mediators, such as adhesion molecules, cytokines, and chemokines released at the site of damage [25]. Inflammatory cells are then recruited and reactive oxygen species (ROS), reactive nitrogen species (RNS), and proinflammatory cytokines are released to eradicate foreign pathogens and thus repair injured tissues [24, 25]. The chronicity of inflammation is dependent on the production of different proteases, ROS and RNS that lead to tissue damage, cell proliferation, and fibrosis during an inflammatory response [24].

In vitro toxicological studies use broad analyses in determining cell viability and cytotoxicity resulting from exposure to chemical substances. As a result, the establishments from in vitro cytotoxicity assays may be employed in predicting the possible human toxicities [16]. Steenkamp and Gouws [26] highlighted that various cell lines exhibit dissimilar sensitivities towards plant extracts.

Therefore, the current study aimed to profile the bioactive compounds in methanolic extract of M. balsamina leaves using molecular spectroscopic (UV-Vis and FTIR) and hyphenated chromatographic (UHPLC-qTOF-MS) techniques as well as evaluating the biological activities of the extract.

\section{Materials and Methods}

2.1. Materials. Analytical grade quality chemicals were used and obtained from a variety of international suppliers. Briefly, UHPLC/MS grade-quality acentronile (Romil, MicroSep, Milford, Massachusetts, USA) and methanol (Romil, MicroSep, Milford, Massachusetts, USA) were used. All solvents used for preliminary phytochemical screening were purchased from Sigma Aldrich (Saint Louis, Missouri, USA). Melphalan was purchased from (GlaxoSmithKline, Brentford, UK) and Griess reagent from (Roche diagnostics, Basel, Switzerland). Anti-inflammatory and cytotoxicity assays were performed at Prof. Van Venter's laboratory (BioAssaix, Nelson Mandela Metropolitan University, Gqeberha South Africa).

2.2. Extraction of Metabolites. The leaves were separated from the twigs and dried at room temperature and subsequently ground into fine powder using a mechanical grinder (Retsch Cutting Mill SM 100, Haan, Germany, Europe). The dried powdered sample was then sealed and kept in a dry area till use for further analysis [27]. Extraction was conducted according to a method described by Makita et al. [21]. Briefly, a mass of $2 \mathrm{~g}$ of the powdered leaf sample was weighed, and $20 \mathrm{ml}$ of $80 \%$ methanol was used for extraction and was sonicated for one hour using an ultrasonic cleaning bath (SB-120DT, Loyal Key Group, Hong Kong). Then, centrifugation was done at $3000 \mathrm{rpm}$ (Thermofisher, Waltham, MA, USA) for 10 minutes at room temperature $\left(25^{\circ} \mathrm{C}\right)$ to collect the supernatant or eradicate the debris from the homogenate. The supernatant was then dried to at least $2 \mathrm{ml}$ of extract using a rotary evaporator under reduced pressure at $55^{\circ} \mathrm{C}$. The extract was then poured into $2 \mathrm{ml}$ cryotubes and further dried overnight at constant air flow in fume hood at $40^{\circ} \mathrm{C}$. Reconstitution of the dried extract was done in $1 \mathrm{ml}$ of $50 \%$ $\mathrm{MeOH}$, and $0.22 \mu \mathrm{m}$ nylon filters were used for filtration. The extract was stored in a freezer at $-20^{\circ} \mathrm{C}$ to avoid degradation until they were used in other assays [21].

\subsection{Preliminary Phytochemical Screening. Preliminary} phytochemical screening tests for cardiac glycosides, flavonoids, phlabotannins, steroids, saponins, terpenoids, and tannins were conducted using methods described by Borokini and Omotayo [28] and Nemudzivhadi and Masoko [29]

2.4. UV-Vis Analysis. The extract was centrifuged at $3000 \mathrm{rpm}$ for 10 minutes to collect the supernatant or remove the debris from the homogenate [21]. The supernatant liquid was then diluted to $1: 10$ with the same solvent. Dilutions were done in $2 \mathrm{ml}$ cryotubes, and the extract was then transferred into 96-well plates. The extract was scanned in wavelength ranging from 200 to $800 \mathrm{~nm}$ using a SpectraMax M3 spectrophotometer (Molecular Devices, California, USA). The distinctive peaks of the UV-Vis were detected, and their values were recorded. Table 1 shows the 
wavelength ranges representing specific secondary metabolites.

2.5. FTIR Analysis. The extract $(2 \mathrm{~g})$ was resuspended in $2 \mathrm{ml}$ of the same solvent; this was done in $2 \mathrm{ml}$ cryotubes. A vortex was used to allow the extract to solubilize, and the tube was placed on shaker for about an hour to allow further solubilisation. The extract was then analysed using ATR-IR FTIR (Alpha 1; Bruker, Germany, Europe). In order to obtain IR spectra, the extract was analysed using the standard procedure in the scanning wave number ranging from 4000 to $500 \mathrm{~cm}^{-1}$ with a resolution of $4 \mathrm{~cm}^{-1}$. Interpretation of IR spectra obtained from extract was achieved by comparing the spectral data with references from identification of functional groups existing in the leaf sample [33-35].

2.6. UHPLC-qTOF-MS Analysis. Ultrahigh-performance liquid chromatography and mass spectroscopy were employed for further profiling of phytoconstituents of M. balsamina. LC-QTOF-MS. Model LC-MS 9030 instrument utilizing Shim Pack Velox C18 column $(100 \mathrm{~mm} \times 2.1 \mathrm{~mm}$ with particle size of $2.7 \mu \mathrm{m})$ (Shimadzu, Kyoto, Japan) was used to analyse $1 \mu \mathrm{l}$ of the extract, which was placed in a column oven set at a temperature of $40^{\circ} \mathrm{C}$. A binary solvent system composed of solvent $\mathrm{A}, 0.1 \%$ formic acid in water, and solvent $\mathrm{B}, 0.1 \%$ formic acid in acetonitrile, was utilized at a flow rate of $0.4 \mathrm{~mL} / \mathrm{min}$. Analytes were chromatographically separated through a 53-minute long gradient method composed of these steps: initially, $10 \% \mathrm{~B}$ for 3 minutes; following this was a step gradient to $60 \% \mathrm{~B}$ above 37 minutes and detained at $60 \% \mathrm{~B}$ for 3 minutes; following this was another gradient to $90 \%$ B for 2 minutes, an isocratic detain at $90 \%$ for 3 min. Finally, the initial conditions $(10 \%$ B) were reestablished conditions in 2 minutes, and the column was reequilibrated for a next run at $10 \%$ B for 3 minutes.

MS detection parameters were set in the following manner: negative electrospray ionization (ESI) modes; an interface voltage of $3.5 \mathrm{kV}$; nebulizer gas flow at $3 \mathrm{~L} / \mathrm{min}$; heating gas flow at $10 \mathrm{~L} / \mathrm{min}$; temperature of heat block at $400^{\circ} \mathrm{C}$; CDL temperature at $250^{\circ} \mathrm{C}$; voltage of detector at $1.70 \mathrm{kV}$ and temperature of TOF tube at $42^{\circ} \mathrm{C}$. Acquisition of high accurate mass with mass error below $1 \mathrm{ppm}$ was ensured by using sodium iodide (NaI) as a mass calibration. For both high-resolution MS and tandem MS (MS/MS) experiments, an $\mathrm{m} / \mathrm{z}$ ranging from 100 to 1000 was employed. For MS/MS experiments, argon gas was utilized as a collision gas, and to generate possible fragments, $\mathrm{MS}^{\mathrm{E}}$ mode utilizing a collision energy ramp of 15 to $25 \mathrm{eV}$ was required.

2.7. In Vitro Cytotoxicity Screening of the M. balsamina Methanolic Extract. A mass of $0.02 \mathrm{~g}$ of extract was weighed, and dimethyl sulfoxide (DMSO) was used as a reconstitution solvent to give a final concentration of $100 \mathrm{mg} / \mathrm{mL}$, followed by sonication of the sample to completely dissolve the extract, and then, it was stored at $4^{\circ} \mathrm{C}$ for further use. The human colorectal adenocarcinoma cell lines (HT29 and Caco2) and African green monkey kidney cells (Vero cells) were used for cytotoxicity screening. These were maintained in $10 \mathrm{~cm}$ culture dishes inside a humidified incubator (Thermofisher, Waltham, MA, USA) with $5 \% \mathrm{CO}_{2}$ at $37^{\circ} \mathrm{C}$. The constituents used for the complete growth medium were Dulbecco's modified Eagle medium (DMEM) supplemented with $10 \%$ foetal bovine serum (FBS) and $10 \%$ penicillinstreptomycin for the three cell lines.

Cells were seeded into 96-well microtiter plates at a density of 4000 cells/well using a volume of $100 \mu \mathrm{l}$ in each well. For cell attachment, the cells were left overnight at $37^{\circ} \mathrm{C}, 5 \%$ $\mathrm{CO}_{2}$, and $100 \%$ relative humidity. Cells were treated with 50 , 100 , and $200 \mu \mathrm{g} / \mathrm{ml}$ of extract. Melphalan, a toxic agent as highlighted by Sigidi et al. [36], was used as a positive control, and volumes of 10,20 , and $40 \mu \mathrm{M}$ were diluted in culture medium. Cells were then further treated with $100 \mu \mathrm{L}$ aliquots of the diluted extract in the fresh medium and incubated again for 48 hours. The treatment medium was aspirated from all wells, and $100 \mu \mathrm{L}$ of Hoechst 33342 nuclear dye $(5 \mu \mathrm{g} / \mathrm{mL})$ was added to each well, followed by incubation for 20 minutes at room temperature $\left(25^{\circ} \mathrm{C}\right)$.

Propidium iodide (PI) was used at $100 \mu \mathrm{g} / \mathrm{mL}$ to stain the cells, and this was done for enumeration of the proportion of dead cells within the population. An image of the cell was then captured immediately after PI was added using the ImageXpress Micro XLS Widefield Microscope (Molecular Devices San Jose, California, USA) with a 10x Plan Fluor objective and DAPI and Texas Red filters cubes. For each well, nine images were acquired as a representative of $75 \%$ of the surface area of the well. For quantifying viable and dead cells, a screening assay was performed, and acquired images were analysed using the MetaXpress software and Multiwavelength Cell Scoring Application Module.

2.8. Anti-Inflammatory Activity of the M. balsamina Leaf Extract. Momordica balsamina extract was dissolved in DMSO to give a final concentration of $100 \mathrm{mg} / \mathrm{ml}$ and diluted further into culture medium. A total of $100 \mu \mathrm{M}$ of aminoguanidine was used as a positive control since it is known as an inhibitor of nitric oxide as highlighted by Sigidi et al. [36]; hence, it was employed as an indicator for antiinflammatory activity.

RAW 264.7 cells were seeded at a density of $1 \times 10^{5}$ cells/ well into 96-well plates and cell attachment took place overnight in a Heracell VIOS $\mathrm{CO}_{2}$ Incubator (Thermofisher, Waltham, MA, USA). Samples were then diluted in DMEM after removal of spent culture medium. These samples were added in volumes of $50 \mu \mathrm{l}$ in each well to give final concentrations of $25,50,100$, and $200 \mu \mathrm{g} / \mathrm{mL}$. The corresponding wells were filled with $50 \mu \mathrm{l}$ of LPS containing medium to give a final concentration of $500 \mu \mathrm{g} / \mathrm{mL}$, and this was done for assessment of anti-inflammatory activity.

2.8.1. Nitrite Production. Aminoguanidine was utilized as a positive control, and cells were further incubated for 18 hours. To quantify NO production, a new 96 -well plate was used, and $50 \mu \mathrm{l}$ of spent culture medium was transferred and 
TABLE 1: Wavelength ranges representing specific secondary metabolites.

\begin{tabular}{lcr}
\hline Absorption maxima (wavelength ranges) & Phytochemical compounds (metabolites) & References \\
\hline $234-676 \mathrm{~nm}$ & Flavonoids, alkaloids, phenolic compounds & {$[17,30]$} \\
$230-285 \mathrm{~nm}$ (band I) & Flavonoids and their derivatives & {$[31]$} \\
$230-290 \mathrm{~nm}$ (band I) & Flavonoids & {$[18,19,32]$} \\
$300-350 \mathrm{~nm}$ (band II) & Flavonoids and their derivatives & {$[18,31,32]$} \\
$350-500 \mathrm{~nm}$ & Tannins & {$[17]$} \\
$400-450 \mathrm{~nm}$ & Carotenoids & {$[17]$} \\
$400-550 \mathrm{~nm}$ & Terpenoids & {$[18,19,32]$} \\
$600-700 \mathrm{~nm}$ & Chlorophyll & {$[18,19,32]$} \\
\hline
\end{tabular}

$50 \mu \mathrm{l}$ Griess reagent was also added. Measurement of absorbance (VersaMax ELISA Microplate Reader, Sunnyvale, CA; USA) was done at $540 \mathrm{~nm}$, and the results were expressed relative to the appropriate untreated control. For the determination of NO concentration in each sample, a standard curve using sodium nitrite dissolved in culture medium was used.

2.8.2. Assessment of Cell Viability. MTT was used to assess cell viability and confirm the absence of toxicity as a contributory factor. This was done by removing the remaining medium and treating each well using a medium comprising of $0.5 \mathrm{mg} / \mathrm{ml} \mathrm{MTT}$ as a replacement and incubating for 30 minutes at $37^{\circ} \mathrm{C}$. MTT was then eradicated and $200 \mu \mathrm{L}$ of DMSO was added to each well to dissolve the formazan crystals. Absorbance was measured at $540 \mathrm{~nm}$ using a spectrophotometer (BioTek ${ }^{\circledR}$ PowerWave XS, Winooski, VT, USA).

\section{Results and Discussion}

A range of techniques have been employed to profile bioactive compounds in plants, and many reports have shown that plants contain numerous secondary metabolites. In this study, molecular spectroscopic (FTIR and UV-Vis) and hyphenated chromatographic (UHPLC-qTOF-MS) techniques were used for plant profiling.

\subsection{Preliminary Phytochemical Screening. Phytochemical} screening tests revealed the presence of tannins, phlobatannins, cardiac glycosides, terpenoids, saponins, and flavonoids with an exception of steroids in the methanolic extract as shown in Table 2.

The findings in this study correspond to the results obtained in a study by Adamu et al. [11], who also detected the presence of tannins, flavonoids, saponins, and glycosides in methanolic extract of $M$. balsamina leaves. However, the difference with the current study is due to the absence of terpenoids. This dissimilarity could be an outcome of geographical and ecological differences $[11,37]$. The outcomes were also different to other studies that detected steroids in the fruit pulp of $M$. balsamina $[1,5]$.

According to Shrestha et al. [38], the presence of cardiac glycosides could mean that the plant is capable of lowering blood pressure. Terpenoids have been reported to exhibit
TABle 2: Preliminary phytochemical screening profile of the M. balsamina extract.

\begin{tabular}{lc}
\hline Metabolites & Methanolic extract \\
\hline Cardiac glycosides & + \\
Flavonoids & + \\
Phlobatannins & + \\
Steroids & - \\
Saponins & + \\
Tannins & + \\
Terpenoids & + \\
\hline
\end{tabular}

(+): present; (-): absent

several biological activities, such as anti-inflammatory [23], immunomodulatory, and antimicrobial activities [38, 39]. Flavonoids and tannins have been reported as free radical scavenging molecules [16, 40, 41]. Saponins are known to possess a significant ability to precipitate and coagulate red blood cells [39] and exhibit anti-inflammatory activity [16].

3.2. UV-Vis Analysis. The UV-Vis profile of the methanolic extract (Figure 1; Table 3) of M. balsamina was selected from $200 \mathrm{~nm}$ to $750 \mathrm{~nm}$ due to broadness of distinctive peaks and proper baseline. This technique was used to detect the presence of phytochemicals by identifying compounds containing $\pi$-bonds, lone pairs of electrons, $\sigma$-bonds, aromatic rings, and chromophores in the UV-Vis region on the electromagnetic spectrum ranging from 200 to $750 \mathrm{~nm}$.

The UV-Vis profile (Figure 1) revealed the presence of 10 peaks at 226, 240, 256, 296, 312, 404, 462, 530, 604, and $658 \mathrm{~nm}$ with absorption ranging from 0.3 to 2.7 a.u., as shown in Table 3. In previous studies, absorption bands that occur at $234-676 \mathrm{~nm}$ are characteristic for alkaloids, flavonoids, and phenolic compounds $[17,30]$; in this case, all peaks occur in this range. This therefore suggests the presence of these secondary metabolites in the extract.

The peaks 226, 240, 256, and 312 were identified as flavonoids and their derivatives and this was due to their occurrence ranging from 230 to 285 (band I) $\mathrm{nm}$ and from 300 to 350 (band II) nm [18, 31, 32]. The presence of aromatic rings and other rings is the reason behind the two absorption spectra for flavonoids and phenolic compounds [17]. In another study, it was also highlighted that the occurrence of peaks ranging from 280 to $330 \mathrm{~nm}$ is characteristic for the phenolic derivatives [19], thus indicating the presence of phenolic compounds in the extract in the current study. 


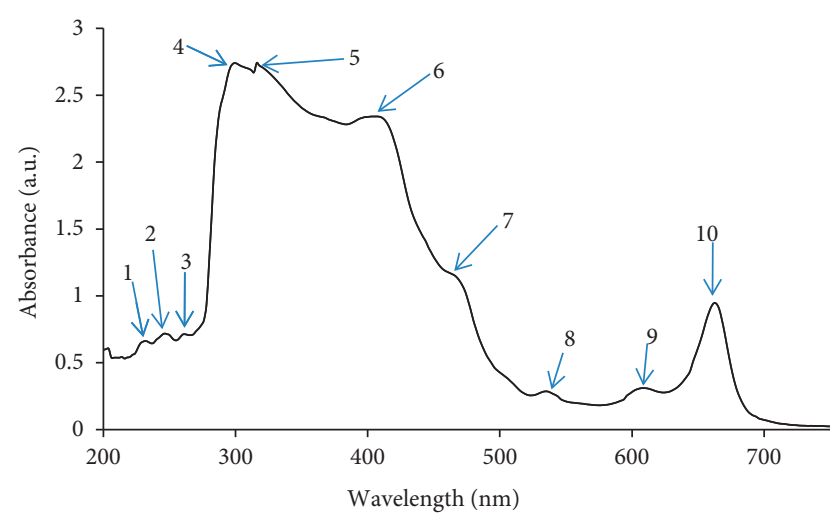

FIGURE 1: UV-visible spectral analysis of the methanolic extract of M. balsamina selected from $200 \mathrm{~nm}$ to $700 \mathrm{~nm}$ due to broadness of distinctive peaks and proper baseline with each arrow indicating characteristic peaks.

TABLE 3: UV-Vis spectrum peak values of the methanolic extract of M. balsamina.

\begin{tabular}{lcc}
\hline S. no. & Wavelength $(\mathrm{nm})$ & Absorbance (a.u.) \\
\hline 1 & 226 & 0.6 \\
2 & 240 & 0.7 \\
3 & 256 & 0.7 \\
4 & 296 & 2.7 \\
5 & 312 & 2.7 \\
6 & 404 & 2.3 \\
7 & 462 & 1.2 \\
8 & 530 & 0.3 \\
9 & 604 & 0.3 \\
10 & 658 & 0.9 \\
\hline
\end{tabular}

The peak 404 was also detected in this study; a previous study highlighted that peaks occurring at $400-450 \mathrm{~nm}$ indicate the presence of carotenoids [17]. The peaks 404 and 462 were also identified, and these were characteristic for tannins due their occurrence at $350-500 \mathrm{~nm}$ [17]. The peaks 404,462 , and 530 were characteristic for terpenoids, and this is due to occurring at $400-550 \mathrm{~nm}[18,32]$. The peaks 604 and 658 were identified as chlorophyll, and this is due to their occurrence at $600-700 \mathrm{~nm}[18,19,32]$.

3.3. FTIR Analysis. FTIR spectral analysis was used to detect functional groups of compounds present in M. balsamina, and this was based on peak values in the region of infrared radiation. When the extract was passed into FTIR, the functional groups of the compounds were separated based on their peak ratios [18]. The FTIR spectral analysis of the methanolic extract (Figure 2) as well as the peak values and functional groups (Table 4) are displayed as follows.

The FTIR spectral analysis of methanolic extract detected the presence of functional groups in six different frequency ranges (Table 4). The FTIR spectrum (Figure 2) showed six major peaks at $3384.84 \mathrm{~cm}^{-1}, 2938.72 \mathrm{~cm}^{-1}, 2039.40 \mathrm{~cm}^{-1}$, $1637.18 \mathrm{~cm}^{-1}, 1084.85 \mathrm{~cm}^{-1}$, and $1029.61 \mathrm{~cm}^{-1}$.

Since aqueous methanol was used to extract the sample, there could be a methanol band in the spectrum (Figure 2).

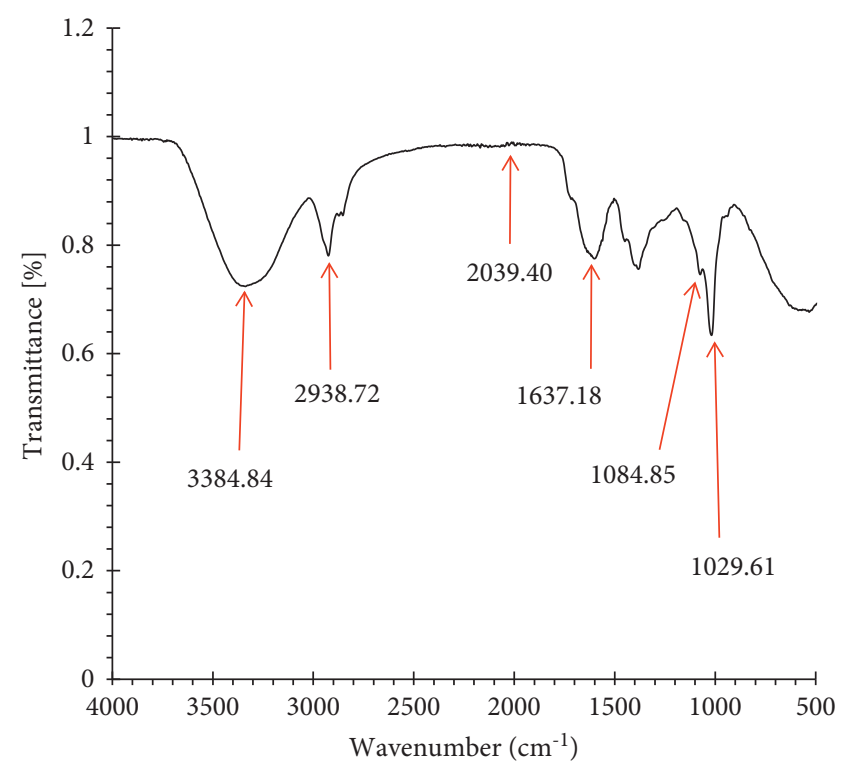

FIGURE 2: FTIR spectrum analysis of the methanolic extract of M. balsamina with each arrow showing distinctive peaks' characteristic for various functional groups indicating specific phytochemical compounds.

Thus, characteristic methanol band would be $3384.84 \mathrm{~cm}^{-1}$ showing stretching vibration of $\mathrm{O}-\mathrm{H}$ group or $\mathrm{O}-\mathrm{H}$ wagging of phenolic compounds [42]. This therefore strongly suggests the presence of phenolic compounds, which have been reported to exhibit antioxidant activities [41].

The analysis revealed the presence of 10 various functional groups belonging to six different compounds as shown in Table 4.

The band occurring at $3384.84 \mathrm{~cm}^{-1}$ indicates that alkaloids may be present which could be due to the $\mathrm{N}-\mathrm{H}$ stretch [31, 43]. The identified band at $2039.40 \mathrm{~cm}^{-1}$ could be due to the presence of alkynes, and this is attributed to the $\mathrm{C} \equiv \mathrm{C}$ stretching vibrations. The stretching vibration of $\mathrm{C}-\mathrm{H}$ band at $2938.72 \mathrm{~cm}^{-1}$ could be ascribed to the presence of $\mathrm{CH}_{2}$ and $\mathrm{CH}_{3}$ group, which indicates the presence of terpenes [31, 43].

The band at $1637.18 \mathrm{~cm}^{-1}$ could be attributed to the presence of a deformed aromatic ring, amino acids, flavonoids, and stretching vibrations of $\mathrm{C}=\mathrm{C}$ groups [33]. The identified bands at $1084.85 \mathrm{~cm}^{-1}$ and $1029.61 \mathrm{~cm}^{-1}$ could be due to presence of $\mathrm{C}-\mathrm{O}$ stretching vibration due to an ester group or secondary alcohol [19].

Fourier transform infrared transmission is very useful in plant characterization because it reveals the presence of inorganic and organic compounds in plants. The presence of functional groups serves as an indicator of different medicinal properties or biological activities of M. balsamina leaves.

3.4. UHPLC-q-MS Analysis. Metabolite extraction and profiling of $M$. balsamina methanolic extract was carried out subsequently. Analyses were done using an LC-qTOF-MS operating in negative electrospray ionization (ESI) mode. From the UHPLC-qTOF-MS chromatogram (Figure 3), a 
TABLE 4: FTIR peak values and functional groups in methanolic extracts of M. balsamina [31, 33, 42, 43].

\begin{tabular}{lccccc}
\hline No. & $\begin{array}{c}\text { Frequency } \\
\text { ranges }\left(\mathrm{cm}^{-1}\right)\end{array}$ & $\begin{array}{c}\text { Frequency peak } \\
\text { values }\left(\mathrm{cm}^{-1}\right)\end{array}$ & Vibration/bond & Specific functional group & Chemical compound \\
\hline 1 & $3600-3200$ & 3384.84 & O-H stretch & Alcohols, phenols (hydrogen bonding) & Aromatic \\
& $3400-3250$ & 3384.84 & N-H stretch & $1^{\circ}, 2^{\circ}$ amines and amides & Amines and amides \\
2 & $3000-2850$ & 2938.72 & C-H stretch & Alkanes & Aliphatic \\
3 & $2270-1940$ & 2039.40 & C $\equiv$ C stretch & Alkynes & Aliphatic \\
4 & $1680-1620$ & 1637.18 & C=C stretch & Alkene & Aliphatic \\
5 & $1320-1000$ & 1084.85 & C-O stretch & Alcohols, carboxylic acids, esters, and ethers and alcohol \\
6 & $1320-1000$ & 1029.61 & C-O & Alcohols, carboxylic acids, esters, and ethers & Acid and alcohol \\
\hline
\end{tabular}

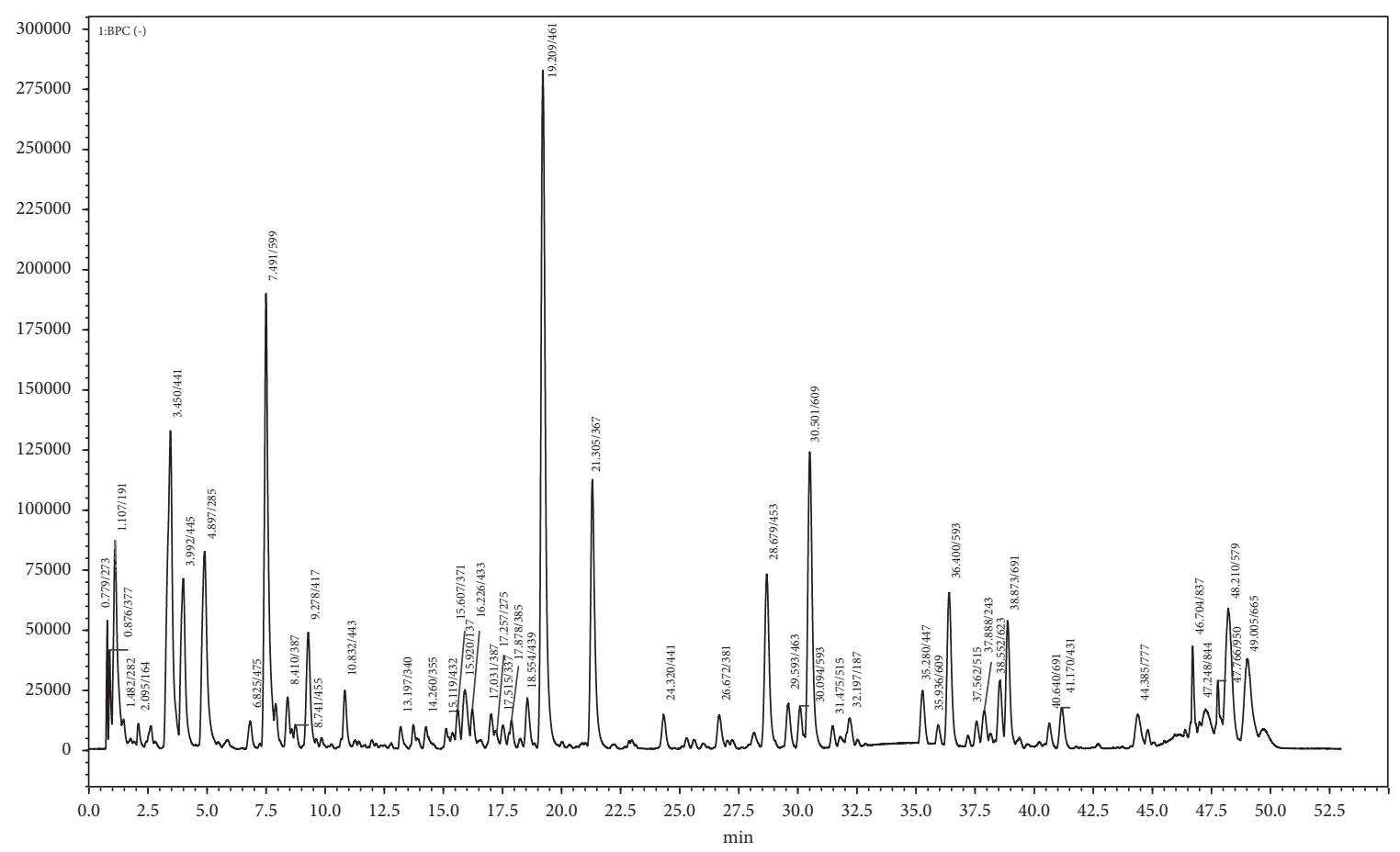

FIgURE 3: Representative UHPLC-qTOF-MS chromatogram showing metabolites present in the methanolic extract of M. balsamina.

total of 12 chromatographic peaks showing various metabolites (Figure 4) were identified as shown in Table 5.

The most common flavonoids are kaempferol, quercetin, and isorhamnetin, and these abundantly exist as glycosides in the plant's tissues [21]. Flavonoids with these aglycones have been reported to exhibit a wide range of health-promoting activities, such as inhibition of inflammation $[44,45]$. Hence, two quercetin-O-glycosides, four kaempferol-O-glycosides, and one isorhamnetin-O-glycoside were identified in this study.

Quercetin has been reported as a crucial dietary flavonoid that is associated with plethora properties capable of suppressing certain ailments linked to chronic diseases [21]. According to Gbashi et al. [46], this flavonoid aglycone has been suggested as a hepatoprotective agent. Quercetin rutinoside (molecule 7 ) with a precursor ion at $m / z 609$ [M$\mathrm{H}]^{-}$was identified in this study. Other studies highlighted that quercetin rutinoside, known as rutin, has high antioxidant activity potential attributing to biological activities such as protection of liver cells and suppression of haemoglobin oxidation $[21,22]$. Furthermore, the molecule has also been reported as an anti-inflammatory agent making it useful in the treatment of chronic diseases [21]. Quercetin hexose (molecule 6) with a precursor ion at $m / z 463[\mathrm{M}-\mathrm{H}]^{-}$ was also detected in current study [21].

Research has shown that kaempferol is of great significance in managing cancer-associated ailments [21, 47] as well as inhibiting oxidative stress [46]. Molecule 10 was identified as kaempferol rutinoside, with a precursor ion at $m / z 593.1496[\mathrm{M}-\mathrm{H}]^{-}$[2]. Molecule 9 was identified as kaempferol hexose $[2,44,46]$, with a precursor ion at $\mathrm{m} / z$ $447[\mathrm{M}-\mathrm{H}]^{-}$. Molecule 2 was identified as kaempferol, with a precursor ion at $m / z 285[\mathrm{M}-\mathrm{H}]^{-}$. Molecule 4 was identified as kaempferol glucuronide [46], with a precursor ion at $m / z$ 461.

Isorhamnetin is a methylated form of quercetin [21], and has been reported to exhibit an anti-inflammatory activity [48]. This flavonoid aglycone has been proven as an 

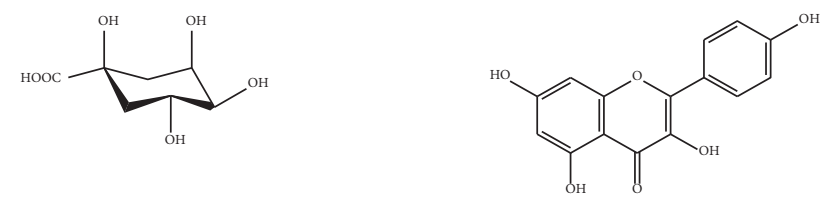

1. Quinic acid<smiles>O=C(O)c1ccc(O[C@@H]2O[C@H](CO)[C@@H](O)[C@H](O)[C@H]2O)cc1</smiles>

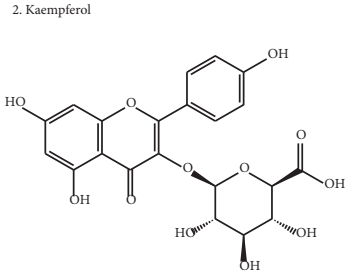

3. Pseudolaroside A acid<smiles>COc1cc(/C=C/C(=O)OC(C(=O)O)C(CC(=O)O)C(=O)O)ccc1C</smiles>

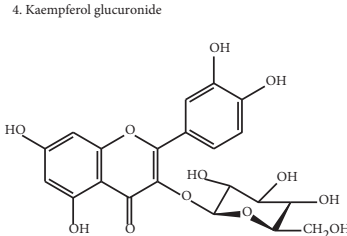

5. Feruloyl isocitric acid
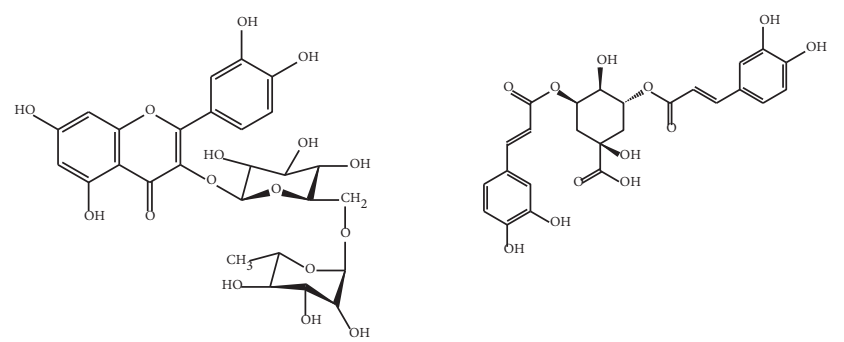

7. Quercetin rutinoside
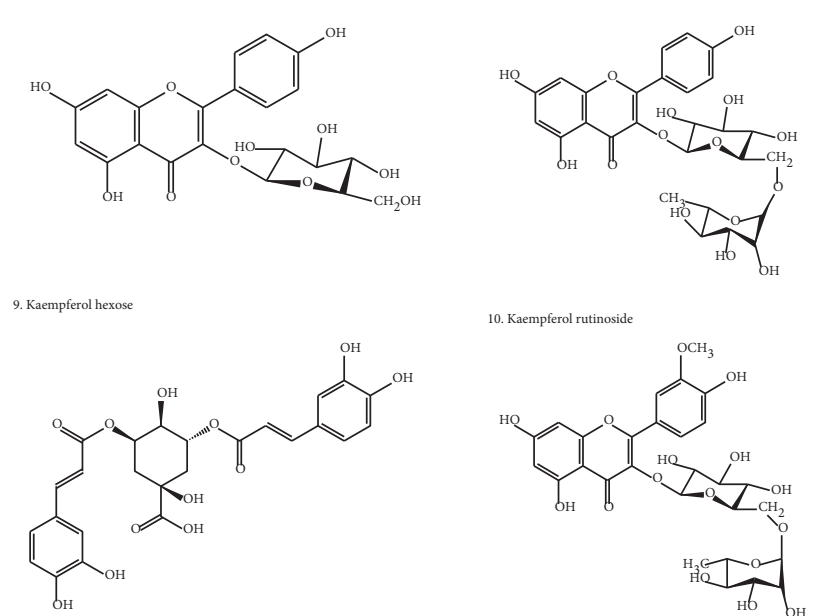

11. 3.5-dicaffeoylquinic acid

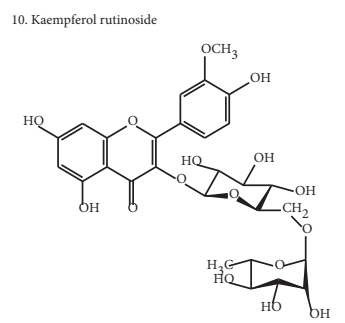

12. sorhamentin rutinoside

FIGURE 4: Chemical structures (1-12) of metabolites isolated from the methanolic extract of $M$. balsamina indicating the presence of flavonoids and acids.

antioxidant agent $[44,49]$. Molecule 12 was identified as isorhamnetin rutinoside, with a precursor ion at $\mathrm{m} / \mathrm{z} 623$ $[\mathrm{M}-\mathrm{H}]^{-}[21]$.

Chlorogenic acids (CGA) are secondary metabolites found in plants and are of great significance because they possess a variety of health benefits, which include anti-inflammatory and antidiabetic activities $[3,50]$. Madala et al.
[3] defined CGA as a molecule that is formed from an ester bond between single or multiple cinnamic acids ( $p$-coumaric, caffeic, and ferulic acid) and quinic acid, resulting in p-coumaroylquinic acid, caffeoylquinic acid, and feruloylquinic acid. A total of three chlorogenic acids were identified, namely, quinic acid with a precursor ion at $\mathrm{m} / z$

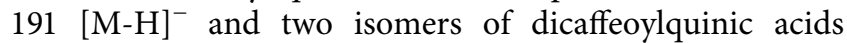
(molecules 8 and 11), with a precursor ion at $\mathrm{m} / z 515$ [M$\mathrm{H}]^{-}$eluted at different retention times, 31.475 and 37.562, respectively (Figure 3; Table 5).

Hydroxyl-cinnamic acids (HCAs) have been reported to exist as positional and geometric isomers conjugated to various organic acids, namely, quinic and isocitric acids $[51,52]$. The formation of hydroxycinnamoyl isocitric acid is due to the formation of a conjugate between HCA derivatives and organic acids, and this includes the esterification between one of the derivatives of HCA and an isocitric acid. This can occur at position 2 (C2) [51]. Masike et al. [51] further highlighted that derivatives of hydroxycinnamoyl isocitric acid are not well documented, and this is ascribed to misidentification of these compounds with monoacyl chlorogenic acids because they have the same molecular mass of conjugates, namely, caffeoyl- (354 Da), p-coumaroyl- $(338 \mathrm{Da})$, and feruloyl- $(368 \mathrm{Da})$. In this study, feruloyl isocitric acid [51] was identified at precursor ion $\mathrm{m} / \mathrm{z}$ $367[\mathrm{M}-\mathrm{H}]^{-}$(molecule 5) as predicted by the accurate highresolution mass spectrometer (LC-QTOF-MS model LC-MS 9030 instrument). To the best of our knowledge, this is the first report on the presence of feruloyl isocitric acid in M. balsamina leaves.

A peculiar compound that has not yet been documented in relation to compounds isolated in M. balsamina was identified in the current study. Pseudolaroside $\mathrm{A}$ acid (molecule 3: $\mathrm{C}_{13} \mathrm{H}_{16} \mathrm{O}_{8}$ ) of precursor ion $\mathrm{m} / z 299$ [M-H] ${ }^{-}$ was identified as a dimer of $\left(\mathrm{C}_{26} \mathrm{H}_{32} \mathrm{O}_{16}\right)$ at precursor ion $m / z 599[\mathrm{M}-\mathrm{H}]^{-}$. This benzoic acid allopyranoside was isolated from the bark of Pseudolarix kaempferi as a colourless amorphous solid by Lui et al. [53]. Kim et al. [54] also isolated this compound from the roots of Coix lachrymaljobi var. mayuen. To the best of our knowledge, only a few studies have been done on this compound, and its significance is yet to be documented.

Nagarani et al. [4] reported other flavonoid molecules in other Momordica species, such as catechin, chlorogenic acid, caffeic acid, and ferulic acid. Previous studies highlighted that these species, namely, M. balsamina, M. charantia, and M. foetida, are abundant sources of flavonoids of different forms, and these include a variety of isomers of the quercetin-, kaempferol-, and isorhamnetin-O-glycosides [2, 44, 55]. In another study by Madala et al. [3], the results revealed that Momordica species are comprised of all forms of common cinnamic acids, such as caffeic, $p$-coumaric, and ferulic acid. In addition, 4-acylated quinic acids were identified: 4- $p$ CoQA, 4-CQA, and 4-FQA.

3.4.1. In Vitro Cytotoxicity Screening of the Methanolic Extract of $M$. balsamina against Human Colorectal Adenocarcinoma (Caco2 and HT29), Vero, and RAW 264.7 Cell 
TABLE 5: UHPLC-qTOF-MS profile of metabolites isolated from the leaf extracts of M. balsamina.

\begin{tabular}{|c|c|c|c|c|}
\hline & Metabolite & Elemental composition & Rt (min) & {$[\mathrm{M}-\mathrm{H}]$} \\
\hline 1 & Quinic acid & $\mathrm{C}_{7} \mathrm{H}_{12} \mathrm{O}_{6}$ & 1.107 & 191 \\
\hline 2 & Kaempferol & $\mathrm{C}_{15} \mathrm{H}_{10} \mathrm{O}_{6}$ & 4.897 & 285 \\
\hline 3 & Pseudolaroside A (dimer) & $\begin{array}{c}\mathrm{C}_{26} \mathrm{H}_{32} \mathrm{O}_{16} \\
\text { Dimer: } \mathrm{C}_{13} \mathrm{H}_{16} \mathrm{O}_{8}\end{array}$ & 7.491 & $\begin{array}{c}599 \\
\text { Dimer: } 299\end{array}$ \\
\hline 4 & Kaempferol glucuronide & $\mathrm{C}_{21} \mathrm{H}_{18} \mathrm{O}_{12}$ & 19.209 & 461 \\
\hline 5 & Feruloyl isocitric acid & $\mathrm{C}_{16} \mathrm{H}_{16} \mathrm{O}_{10}$ & 21.305 & 367 \\
\hline 6 & Quercetin hexose & $\mathrm{C}_{21} \mathrm{H}_{20} \mathrm{O}_{12}$ & 29.5923 & 463 \\
\hline 7 & Quercetin rutinoside & $\mathrm{C}_{27} \mathrm{H}_{30} \mathrm{O}_{16}$ & 30.501 & 609 \\
\hline 8 & Dicaffeoylquinic acid isomer I & $\mathrm{C}_{25} \mathrm{H}_{24} \mathrm{O}_{12}$ & 31.475 & 515 \\
\hline 9 & Kaempferol hexose & $\mathrm{C}_{21} \mathrm{H}_{20} \mathrm{O}_{11}$ & 35.936 & 447 \\
\hline 10 & Kaempferol rutinoside & $\mathrm{C}_{27} \mathrm{H}_{30} \mathrm{O}_{15}$ & 36.400 & 593 \\
\hline 11 & Dicaffeoylquinic acid isomer II & $\mathrm{C}_{25} \mathrm{H}_{24} \mathrm{O}_{12}$ & 37.562 & 515 \\
\hline 12 & Isorhamnetin rutinoside & $\mathrm{C}_{27} \mathrm{H}_{30} \mathrm{O}_{16}$ & 38.552 & 623 \\
\hline
\end{tabular}
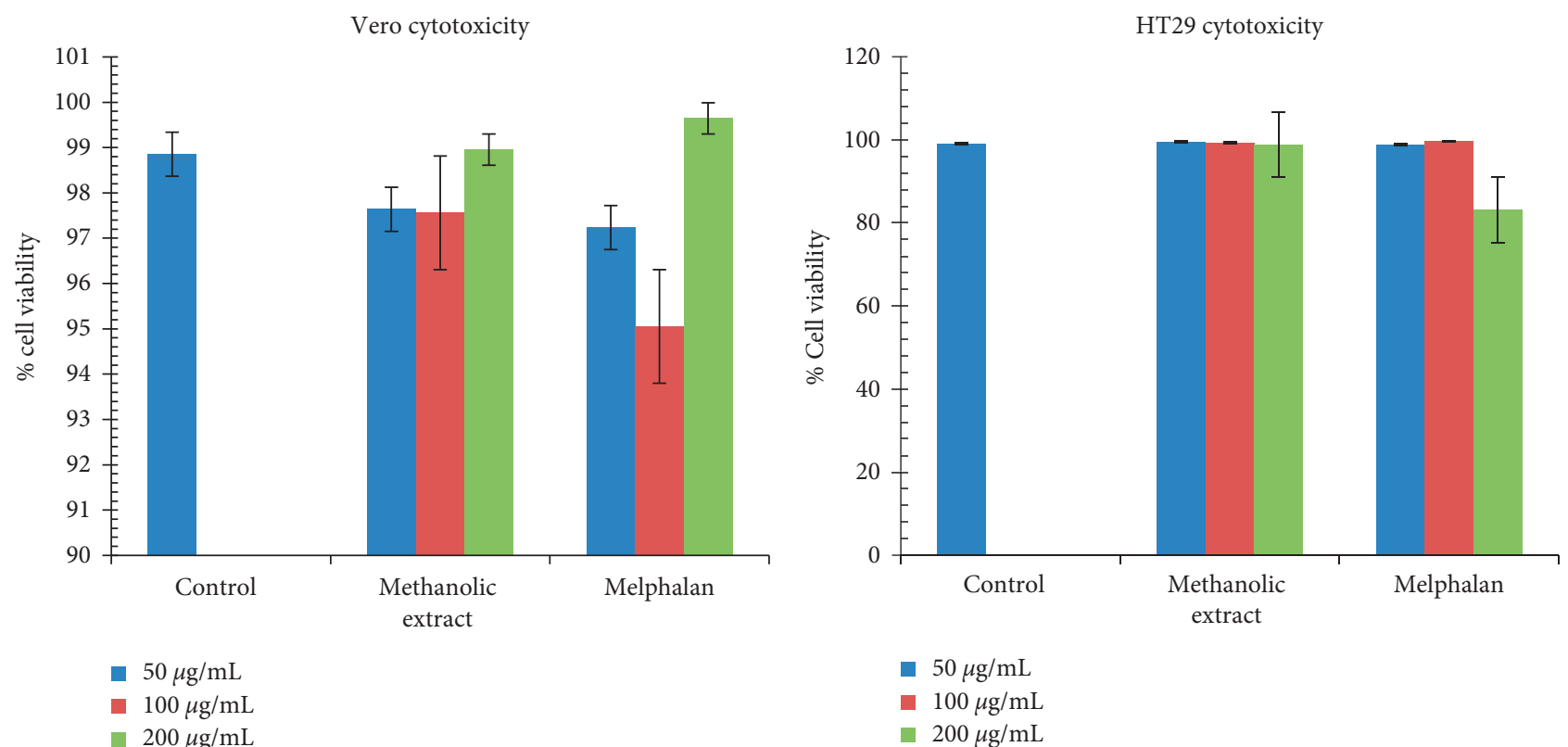

(a)

(b)

Figure 5: Continued. 


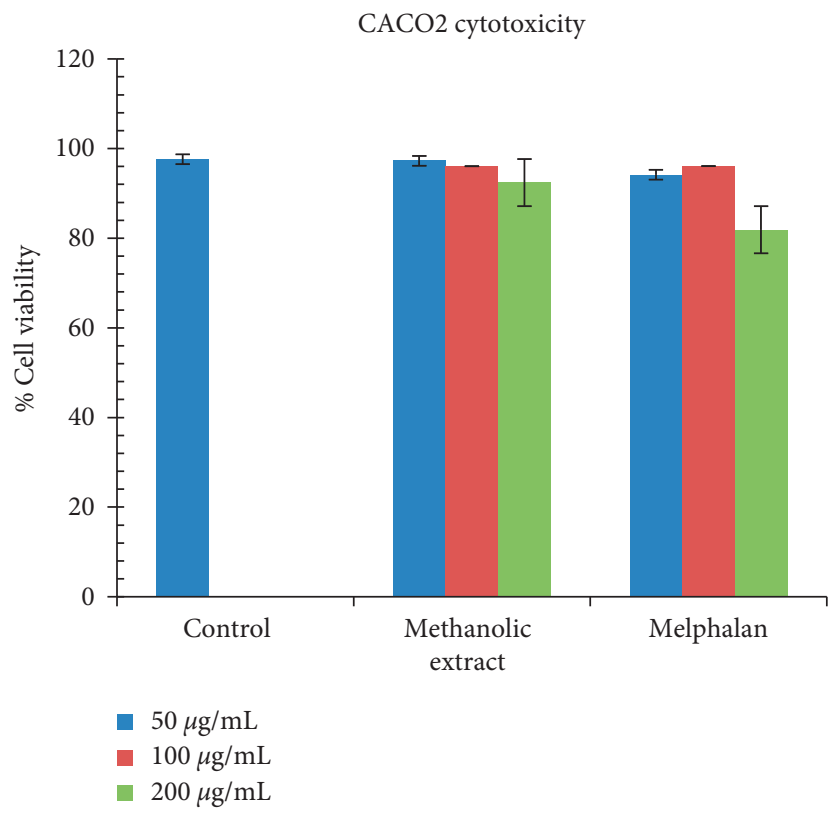

(c)

Figure 5: Cytotoxicity analysis of the methanolic extract of M. balsamina against three cell lines, namely, Vero cytotoxicity (a), HT29 cytotoxicity (b), and Caco2 cytotoxicity (c), at 3 concentrations. Melphalan was employed as a positive control.

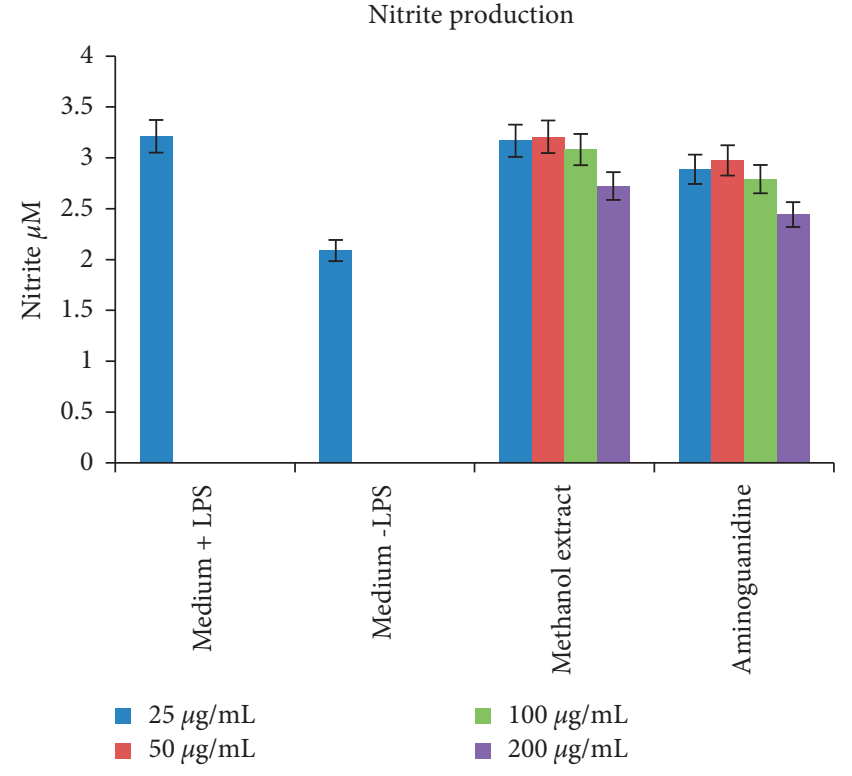

(a)

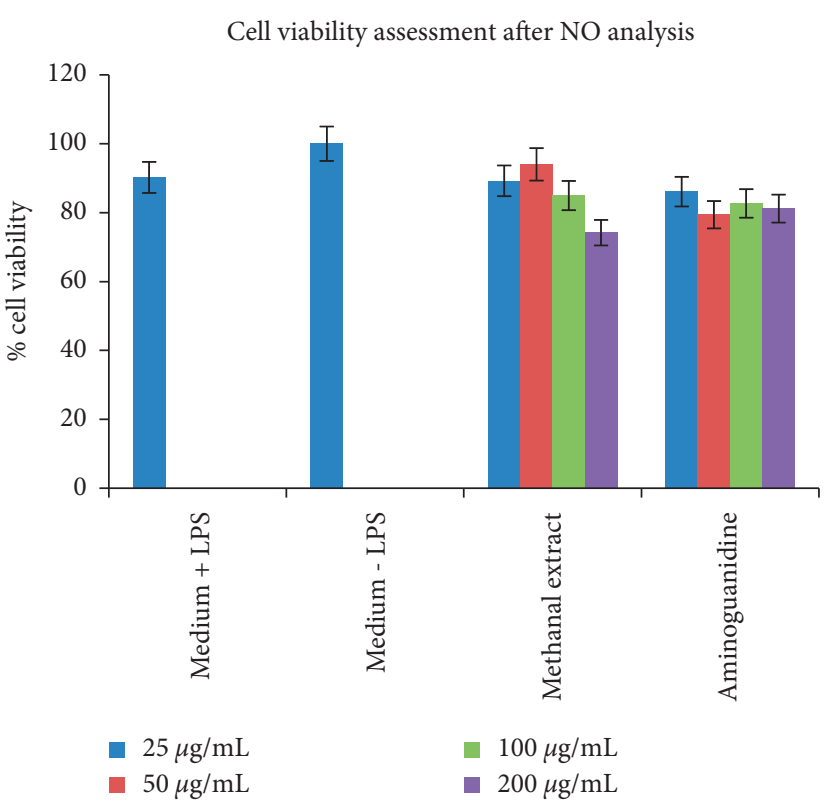

(b)

Figure 6: Anti-inflammatory analysis of the M. balsamina methanolic extract in RAW 264.7 cell lines. (a) The effect of the methanolic plant extract on the production of nitrate and cell viability in LPS-stimulated and unstimulated RAW macrophages. (b) Aminoguanidine, an inhibitor of iNOS expression serving as a positive control to confirm the functionality of the assay.

Lines. The cytotoxic effects of the extract against Caco2, HT29, and Vero cell lines were assessed and evaluated using MTT assay. In all the three cell lines tested, no cytotoxic effect was observed. The extract exhibited no cytotoxicity in Caco2, HT29, RAW 264.7, and Vero cell lines (Figures 5(a)5(c), resp.).
Medicinal plants may be considered effective in clinical applications if the preparations show selective toxicity to the targeted microorganism [56]. The findings confirmed that M. balsamina leaves have no cytotoxic activity against human colorectal adenocarcinoma cell lines HT29 and Caco2. The methanolic extract showed less toxicity compared with 
melphalan standard as presented in Figure 5(a). Cell viability at the highest concentration $(200 \mu \mathrm{g} / \mathrm{ml})$ of the extract was above $98 \%$, which is comparable with cells, only control. Based on the visual inspection of cell viability of extract against all cell lines (Figures 5(a)-5(c)), cell viability was not affected or did not decrease even in the presence of the extract, strongly suggesting that these leaves are safe for consumption.

According to a study done by Ramalhete et al. [57], M. balsamina compounds showed no cytotoxicity against human breast cancer (MCF-7) cell lines. Furthermore, in vivo studies have demonstrated that $M$. balsamina extracts have shown an extremely weak or inactive toxicity $[7,57]$. In another study by Ramalhete et al. [58] on the activity of $M$. balsamina against bacterial efflux pumps, the extracts showed no toxicity against human lymphocytes [58]. These findings support the observed lack of toxicity of M. balsamina extracts despite the diversity of the phytochemicals detected.

3.4.2. In Vitro Anti-Inflammatory Screening of the Methanolic Extract of M. balsamina on RAW 264.7 Cell Lines. The in vitro anti-inflammatory potential of $M$. balsamina methanolic extract was evaluated on RAW 264.7 cells. The observed results (Figures 6(a) and 6(b)) indicated that the methanolic extract at the highest concentration $(200 \mu \mathrm{g} / \mathrm{ml})$ exhibited potential anti-inflammatory activity. This is due to the presence of anti-inflammatory exhibiting compounds, such as flavonoids and phenolic compounds, as identified by the phytochemical analyses conducted in this study. In support of the results obtained in this study, Nagarani et al. [4] highlighted that Momordica species have potential antiinflammatory activity, and it is possible that the anti-inflammatory effects may be correlated to the phytochemical composition of the plant.

A study by Thakur et al. [5] revealed that the methanolic extract of M. balsamina exhibited anti-inflammatory activity and this is in agreement with the current study. Sigidi et al. [36] defined $\mathrm{NO}$ as an intracellular free radical that can be generated in different mammalian cells. This molecule plays a role in neurotransmission, acute and chronic inflammation, and host defense mechanisms against different pathogenic microbes. However, it may induce a toxic reaction against the host's tissues if produced in higher levels $[36,56]$.

In this study, flavonoids were detected in the extract and have been reported as naturally occurring anti-inflammatory agents [59]. In support of that statement, a few studies have reported flavonoids to have anti-inflammatory properties through inhibition of transcription factors and regulatory enzymes that play a crucial role in controlling inflammatory mediators $[24,25]$. Therefore, flavonoids exhibit an antiinflammatory activity. It is important to highlight that antiinflammatory activity of M. balsamina extract may be linked to the presence of flavonoids.

Qualitative and quantitative analyses of the phytochemical composition and toxicological effects of Momordica leaves are pivotal because these leaves can be suitable for incorporation into functional food in consideration of traditional and scientific knowledge of diverse assessments [4].

\section{Conclusions}

In this study, it was confirmed that Momordica balsamina contains a wide variety of secondary metabolites that could be of medicinal importance. The study also demonstrated that the leaves could be used as anti-inflammatory agents and are nontoxic to the colorectal adenocarcinoma cell lines, thus making them safe for consumption. This is the first study to report pseudolaroside A acid and feruloyl isocitric acid in Momordica balsamina leaves. Further investigations on these compounds and their significances are necessary.

\section{Data Availability}

The supporting data can be provided from the corresponding author upon request.

\section{Conflicts of Interest}

The authors declare that there are no conflicts of interest regarding the publication of this paper.

\section{Acknowledgments}

The authors would like to acknowledge the University of Venda for supplying appropriate laboratory equipment to execute this work, Professor Van Venter for assisting with the in vitro bioassays in her laboratory at Nelson Mandela Metropolitan University in Gqeberha, South Africa, and the National Research Foundation (NRF) for the financial assistance.

\section{References}

[1] Y. S. Bot, L. O. Mgbojikwe, C. Nwosu, A. Abimiku, J. Dadik, and D. Damshak, "Screening of the fruit pulp extract of Momordica balsamina for anti-HIV property," African Journal of Biotechnology, vol. 6, no. 1, pp. 047-052, 2007.

[2] N. E. Madala, L. Piater, I. Dubery, and P. Steenkamp, "Distribution patterns of flavonoids from three Momordica species by ultra-high performance liquid chromatography quadrupole time of flight mass spectrometry: a metabolomic profiling approach," Revista Brasileira de Farmacognosia, vol. 26, no. 4, pp. 507-513, 2016.

[3] N. E. Madala, F. Tugizimana, and P. A. Steenkamp, "Development and optimization of an UPLC-QTOF-MS/MS method based on an in-source collision induced dissociation approach for comprehensive discrimination of chlorogenic acids isomers from Momordica plant species," Journal of analytical methods in chemistry, vol. 7, Article ID 650879, 2014.

[4] G. Nagarani, A. Abirami, and P. Siddhuraju, "A comparative study on antioxidant potentials, inhibitory activities against key enzymes related to metabolic syndrome, and anti-inflammatory activity of leaf extract from different Momordica species," Food Science and Human Wellness, vol. 3, no. 1, pp. 36-46, 2014.

[5] G. Thakur, M. Bag, B. Sanodiya et al., "Momordica balsamina: a medicinal and neutraceutical plant for health care 
management," Current Pharmaceutical Biotechnology, vol. 10, no. 7, pp. 667-682, 2009.

[6] G. S. Thakur, M. Pandey, R. Sharma, B. S. Sanodiya, G. B. K. S. Prasad, and P. S. Bisen, "Factors affecting in vitro propagation of Momordica balsamina: a medicinal and nutritional climber," Physiology and Molecular Biology of Plants, vol. 17, no. 2, pp. 193-197, 2011.

[7] F. Benoit-Vical, P. Grellier, A. Abdoulaye et al., "In vitro and in vivo antiplasmodial activity of Momordica balsamina alone or in a traditional mixture," Chemotherapy, vol. 52, no. 6, pp. 288-292, 2006.

[8] A. H. Kgopa, L. J. Shai, and M. A. Mogale, "Momordica balsamina fruit extracts enhances selected aspects of the insulin synthesis/secretion pathway," American Journal of Biochemistry and Biotechnology, vol. 16, no. 4, pp. 549-560, 2020.

[9] A. Siboto, N. Sibiya, A. Khathi, and P. Ngubane, "The effects of Momordica balsamina methanolic extract on kidney function in STZ-induced diabetic rats: effects on selected metabolic markers," Journal of diabetes research, vol. 8, Article ID $7341242,2018$.

[10] S. O. Otimenyin, M. O. Uguru, and A. Ogbonna, "Antimicrobial and hypoglycemic effects of Momordica balsamina. Linn," Journal of Natural Products, vol. 1, pp. 3-9, 2008.

[11] H. M. Adamu, O. A. Ushie, E. Ogah, B. Longbap, and A. U. Dawud, "Phytochemical screening and antimicrobial activities of the leaf extracts of Momordica balsamina," Ewemen Journal of Microbial Research, vol. 1, no. 1, pp. 16-19, 2015.

[12] P. K. Ajji, K. Walder, and M. Puri, "Functional analysis of a type-I ribosome inactivating protein balsamin from Momordica balsamina with anti-microbial and DNase activity," Plant Foods for Human Nutrition, vol. 71, no. 3, pp. 265-271, 2016.

[13] U. Shamsuddeen, H. Haruna, A. A. Dantata, and A. D. Usman, "Incidence of staphylococcus spp and some members of enterobacteriaceae family and their susceptibilty to leaf extracts of Momordica balsamina (balsam apple)," Bayero Journal of Pure and Applied Sciences, vol. 3, no. 2, pp. 148-152, 2010.

[14] S. Souda, S. George, N. Mannathoko, I. Goercke, and K. Chabaesele, "Antioxidant and antibacterial activity of methanol extract of Momordica balsamina," IRA-International Journal of Applied Sciences (ISSN 2455-4499), vol. 10, no. 2, pp. 7-17, 2018.

[15] S. Chandra, "Fourier transform infrared (Ft-Ir) spectroscopic analysis of Nicotiana plumbaginifolia (Solanaceae)," Journal of Medicinal Plants, vol. 7, no. 1, pp. 82-85, 2019.

[16] M. M. Matotoka and P. Masoko, "Phytochemical screening and pharmacological evaluation of herbal concoctions sold at Ga Maja Limpopo Province," South African Journal of Botany, vol. 117, pp. 1-10, 2018.

[17] T. K. Patle, K. Shrivas, R. Kurrey, S. Upadhyay, R. Jangde, and R. Chauhan, "Phytochemical screening and determination of phenolics and flavonoids in Dillenia pentagyna using UV-vis and FTIR spectroscopy," Spectrochimica Acta Part A: Molecular and Biomolecular Spectroscopy, vol. 242, Article ID 118717, 2020.

[18] M. Saxena and J. Saxena, "Evalution of phytoconstituents of Acorus calamus by FTIR and UV-VIS spectroscopic analysis," International Journal of Biological and Pharmaceutical Research, vol. 3, no. 3, pp. 498-501, 2012.

[19] M. Johnson and M. Syed Ali Fathima, "Spectroscopic studies on pouzolzia wightii benn," International Journal of
Pharmacy and Pharmaceutical Sciences, vol. 10, no. 3, pp. 124-132, 2018.

[20] D. I. Njoku, M. A. Chidiebere, K. L. Oguzie, C. E. Ogukwe, and E. E. Oguzie, "Corrosion inhibition of mild steel in hydrochloric acid solution by the leaf extract of Nicotiana tabacum," Advances in Materials and Corrosion, vol. 2, no. 1, pp. 54-61, 2013.

[21] C. Makita, L. Chimuka, P. Steenkamp, E. Cukrowska, and E. Madala, "Comparative analyses of flavonoid content in Moringa oleifera and Moringa ovalifolia with the aid of UHPLC-qTOF-MS fingerprinting," South African Journal of Botany, vol. 105, pp. 116-122, 2016.

[22] C. Rodríguez-Pérez, R. Quirantes-Piné, A. FernándezGutiérrez, and A. Segura-Carretero, "Optimization of extraction method to obtain a phenolic compounds-rich extract from Moringa oleifera Lam leaves," Industrial Crops and Products, vol. 66, pp. 246-254, 2015.

[23] N. P. Nthulane, S. Mosebi, T. E. Tshikalange, M. A. Nyila, and L. T. Mankga, "Antimicrobial and anti-inflammatory activities of selected medicinal plants against pathogens causing sexually transmitted infections," Journal of Herbmed Pharmacology, vol. 9, no. 2, pp. 130-137, 2020.

[24] S. J. Maleki, J. F. Crespo, and B. Cabanillas, "Anti-inflammatory effects of flavonoids," Food Chemistry, vol. 299, Article ID 125124, 2019.

[25] S. Kumar and A. K. Pandey, "Chemistry and biological activities of flavonoids: an overview," Science World Journal, vol. 2013, Article ID 162750, 16 pages, 2013.

[26] V. Steenkamp and M. C. Gouws, "Cytotoxicity of six South African medicinal plant extracts used in the treatment of cancer," South African Journal of Botany, vol. 72, no. 4, pp. 630-633, 2006.

[27] N. Jaradat, A. Eid, F. Abdelwahab et al., "Phytochemical analysis, quantitative estimations of total phenols and free radical scavenging activity of Bupleurum subovatum from Jerusalem," Pharmaceutical Sciences, vol. 21, no. 4, pp. 205-210, 2015.

[28] T. I. Borokini and F. O. Omotayo, "Phytochemical and ethnobotanical study of some selected medicinal plants from Nigeria," Journal of Medicinal Plants Research, vol. 6, no. 7, pp. 1106-1118, 2012.

[29] V. Nemudzivhadi and P. Masoko, "Antioxidant and antibacterial properties of Ziziphus mucronata and Ricinus communis leaves extracts," African Journal of Traditional, Complementary and Alternative Medicines, vol. 12, no. 1, pp. 81-89, 2015.

[30] C. Karpagasundari and S. Kulothungan, "Analysis of bioactive compounds in Physalis minima leaves using GC MS, HPLC, UV-VIS and FTIR techniques," Journal of Pharmacognosy and Phytochemistry, vol. 3, no. 4, pp. 196-201, 2014.

[31] K. Kalaichelvi and S. M. Dhivya, "Screening of phytoconstituents, UV-VIS spectrum and FTIR analysis of micrococca mercurialis (L.) benth," International Journal of Herbal Medicine, vol. 5, no. 6, pp. 40-44, 2017.

[32] B. Renuka, B. Sanjeev, and D. Ranganathan, "Evaluation of phytoconstituents of Caralluma nilagiriana by FTIR and UVVIS spectroscopic analysis," Journal of Pharmacognosy and Phytochemistry, vol. 5, no. 2, p. 105, 2016.

[33] O. R. Alara, N. H. Abdurahman, S. K. A. Mudalip, and O. A. Olalere, "Characterization and effect of extraction solvents on the yield and total phenolic content from Vernonia amygdalina leaves," Journal of Food Measurement and Characterization, vol. 12, no. 1, pp. 311-316, 2018. 
[34] R. Ashokkumar and M. Ramaswamy, "Phytochemical screening by FTIR spectroscopic analysis of leaf extracts of selected Indian Medicinal plants," International journal of Current Microbiology and Applied Sciences, vol. 3, no. 1, pp. 395-406, 2014.

[35] S. Sravan Kumar, P. Manoj, and P. Giridhar, "Fourier transform infrared spectroscopy (FTIR) analysis, chlorophyll content and antioxidant properties of native and defatted foliage of green leafy vegetables," Journal of Food Science and Technology, vol. 52, no. 12, pp. 8131-8139, 2015.

[36] M. T. Sigidi, A. N. Traoré, M. M. Boukandou, M. P. Tshisikhawe, S. S. Ntuli, and N. Potgieter, "Anti-HIV, pro-inflammatory and cytotoxicity properties of selected Venda plants," Indian Journal of Traditional Knowledge, vol. 16, no. 4, pp. 545-552, 2017.

[37] I. Y. Sudi, D. M. Ksgbiya, E. K. Muluh, and A. Clement, "Nutritional and phytochemical screening of Senna obtusifolia indigenous to Mubi, Nigeria," Advances in Applied Science Research, vol. 2, no. 3, pp. 432-437, 2011.

[38] P. Shrestha, M. Bista, P. Sharma et al., "Phytochemical screening, antimicrobial activity and cytotoxicity of Nepalese medicinal plants Swertia chirayita and Dendrobium amoenum," Nepal Journal of Biotechnology, vol. 3, no. 1, pp. 48-57, 2015.

[39] G. Watal, P. Dhar, S. K. Srivastava, and B. Sharma, "Herbal medicine as an alternative medicine for treating diabetes: the global burden," Evidence-based Complementary and Alternative Medicine, vol. 2, Article ID 596071, 2014.

[40] S. R. Biradar and B. D. Rachetti, "Extraction of some secondary metabolites \&thin layer chromatography from different parts of Centella asiatica L. (URB)," American Journal of Life Sciences, vol. 1, no. 6, pp. 243-247, 2013.

[41] P. Masoko and J. N. Eloff, "Screening of twenty-four South African Combretum and six Terminalia species (Combretaceae) for antioxidant activities," African Journal of Traditional, Complementary and Alternative Medicines, vol. 4, no. 2, pp. 231-239, 2007.

[42] R. N. Oliveira, M. C. Mancini, F. C. S. d. Oliveira et al., "FTIR analysis and quantification of phenols and flavonoids of five commercially available plants extracts used in wound healing," Matèria. Revista Internacional d'Art, vol. 21, no. 3, pp. 767-779, 2016.

[43] P. S. Were, W. Waudo, H. S. Ozwara, and H. L. Kutima, "Phytochemical analysis of warburgia ugandensis sprague using fourier transform infra-red (FT-IR) spectroscopy," International Journal of pharmacognosy and Phytochemical Research, vol. 7, no. 2, pp. 201-205, 2015.

[44] B. S. Khoza, I. A. Dubery, H.-A. Byth-Illing, P. A. Steenkamp, L. Chimuka, and N. E. Madala, "Optimization of pressurized hot water extraction of flavonoids from Momordica foetida using UHPLC-qTOF-MS and multivariate chemometric approaches," Food Analytical Methods, vol. 9, no. 6, pp. 1480-1489, 2016.

[45] J. Xiao, G.-B. Sun, B. Sun et al., "Kaempferol protects against doxorubicin-induced cardiotoxicity in vivo and in vitro," Toxicology, vol. 292, no. 1, pp. 53-62, 2012.

[46] S. Gbashi, P. Njobeh, P. Steenkamp, and N. Madala, "Pressurized hot water extraction and chemometric fingerprinting of flavonoids from Bidens pilosa by UPLC-tandem mass spectrometry," CyTA-Journal of Food, vol. 15, no. 2, pp. 171-180, 2017.

[47] A. Y. Chen and Y. C. Chen, "A Review on dietary flavonoids, kaempferol on (human health and cancer chemoprevention," Food Chemistry, vol. 15, pp. 2009-2107, 2013.
[48] M. Antunes-Ricardo, J. A. Gutiérrez-Uribe, F. López-Pacheco, M. M. Alvarez, and S. O. Serna-Saldívar, "In vivo anti-inflammatory effects of isorhamnetin glycosides isolated from Opuntia ficus-indica (L.) Mill cladodes," Industrial Crops and Products, vol. 76, pp. 803-808, 2015.

[49] Y.-J. Xu, M. Kaur, R. S. Dhillon, P. S. Tappia, and N. S. Dhalla, "Health benefits of sea buckthorn for the prevention of cardiovascular diseases," Journal of Functional Foods, vol. 3, no. 1, pp. 2-12, 2011.

[50] M. M. Makola, P. A. Steenkamp, I. A. Dubery, M. M. Kabanda, and N. E. Madala, "Preferential alkali metal adduct formation by cis geometrical isomers of dicaffeoylquinic acids allows for efficient discrimination from their trans isomers during ultra-high-performance liquid chromatography/quadrupole time-of-flight mass spectrometry," Rapid Communications in Mass Spectrometry, vol. 30, no. 8, pp. 1011-1018, 2016.

[51] K. Masike, M. I. Mhlongo, S. P. Mudau et al., "Highlighting mass spectrometric fragmentation differences and similarities between hydroxycinnamoyl-quinic acids and hydroxycinnamoyl-isocitric acids," Chemistry Central Journal, vol. 11, no. 1, pp. 29-37, 2017.

[52] I. Parveen, A. Winters, M. D. Threadgill, B. Hauck, and P. Morris, "Extraction, structural characterisation and evaluation of hydroxycinnamate esters of orchard grass (Dactylis glomerata) as substrates for polyphenol oxidase," Phytochemistry, vol. 69, no. 16, pp. 2799-2806, 2008.

[53] P. Lui, H. Guo, Y. Tian, Q. Wang, and D. Guo, "Benzoic acid allopyranosides from the bark of Pseudolarix kaempferi," Phytochemistry, vol. 67, pp. 1395-1398, 2006.

[54] S. Y. Kim, C. W. Choi, S. S. Hong, H. Shin, and J. S. Oh, "A new neolignan from Coix lachryma-jobi var. mayuen," Natural product communications, vol. 11, no. 2, Article ID 1934578X1601100224, 2016.

[55] W. A. S. Guarniz, K. M. Canuto, P. R. V. Ribeiro et al., "Momordica charantia L. Variety from northeastern Brazil: analysis of antimicrobial activity and phytochemical components," Pharmacognosy Journal, vol. 11, no. 6, pp. 366-370, 2019.

[56] M. T. Sigidi, C. P. Anokwuru, T. Zininga et al., "Comparative in vitro cytotoxic, anti-inflammatory and anti-microbiological activities of two indigenous Venda medicinal plants," Translational Medicine Communications, vol. 1, no. 1, p. 9, 2016.

[57] C. Ramalhete, D. Lopes, S. Mulhovo, J. Molnár, V. E. Rosário, and M.-J. U. Ferreira, "New antimalarials with a triterpenic scaffold from Momordica balsamina," Bioorganic and Medicinal Chemistry, vol. 18, no. 14, pp. 5254-5260, 2010.

[58] C. Ramalhete, G. Spengler, A. Martins et al., "Inhibition of efflux pumps in meticillin-resistant Staphylococcus aureus and Enterococcus faecalis resistant strains by triterpenoids from Momordica balsamina," International Journal of Antimicrobial Agents, vol. 37, no. 1, pp. 70-74, 2011.

[59] M. A. Read, "Flavonoids: naturally occurring anti-inflammatory agents," American Journal of Pathology, vol. 147, no. 2, pp. 235-237, 1995. 